\title{
Valine, a Branched-Chain Amino Acid, Reduced HCV Viral Load and Led to Eradication of HCV by Interferon Therapy in a Decompensated Cirrhotic Patient
}

\author{
Takumi Kawaguchi $^{\text {a-c }}$ Takuji Torimura ${ }^{a, c} \quad$ Akio Takata $^{a}$ \\ Susumu Satomi ${ }^{d}$ Michio Sata ${ }^{a-c}$ \\ ${ }^{a}$ Division of Gastroenterology, Department of Medicine and ${ }^{b}$ Department of \\ Digestive Disease Information and Research, Kurume University School of \\ Medicine, Kurume, ' Liver Cancer Research Division, Research Center for \\ Innovative Cancer Therapy, Kurume University, Kurume, and ${ }^{\mathrm{d}}$ Division of \\ Advanced Surgical Science and Technology, Graduate School of Medicine, \\ Tohoku University, Sendai, Japan
}

\section{Key Words}

Valine $\cdot$ Branched-chain amino acid $\cdot$ Hepatitis $C$ virus $\cdot$ Viral kinetics

\begin{abstract}
A decreased serum level of branched-chain amino acid (BCAA) is a distinctive metabolic disorder in patients with liver cirrhosis. Recently, BCAA has been reported to exert various pharmacological activities, and valine, which is a BCAA, has been shown to affect lipid metabolism and the immune system in in vivo experiments. However, the clinical impact of valine supplementation on viral hepatitis $\mathrm{C}$ virus (HCV) load has never been reported. Here, we first describe a case of HCV-related advanced liver cirrhosis that was treated by an oral valine agent. The administration of valine resulted in an improvement of fatigue and a reduction in hepatic fibrosis indexes as well as serum $\alpha$-fetoprotein level. Furthermore, a marked reduction in HCV RNA levels was seen after valine treatment. The patient was then treated by interferon $\beta$, resulting in the successful eradication of chronic HCV infection. Thus, valine may be involved in the reduction of HCV viral load and could support a sustained virologic response to interferon therapy.
\end{abstract}




\section{Introduction}

Chronic hepatitis C virus (HCV) infection is a frequent cause of serious liver disease and an estimated 180 million people are infected worldwide [1]. Although interferon is a potent antiviral agent for chronic HCV infection, response to interferon therapy is influenced by various factors, including age, obesity, insulin resistance, HCV genotype, amino acid substitution in the HCV core protein, and interleukin-28B gene polymorphism [1-3]. Viral load has also been recognized as an important factor, and a high viral load is associated with poor response to interferon therapy [4].

Amino acid imbalance is a distinctive metabolic disorder in patients with liver cirrhosis, and the serum level of branched-chain amino acid (BCAA) is decreased [5]. BCAA is not only a constituent of protein, but has also been recently reported as a pharmacological nutrient [5-8]. BCAA is comprised of valine, leucine and isoleucine. In particular, valine has been shown to cause maturation of monocyte-derived dendritic cells (DCs) from patients with HCV-related liver cirrhosis and to also increase their interleukin-12 production [9]. On the other hand, valine-depleted nutrition causes the accumulation of hepatic lipid droplets [10]. Both immune function and hepatic triglycerides are associated with HCV replication [11]. Moreover, BCAA has recently been reported to activate interferon signaling and to inhibit HCV replication through the activation of the mammalian target of rapamycin (mTOR) and the downregulation of the suppressor of cytokine signaling 3 (SOCS3) [12], suggesting that valine may suppress HCV replication. However, the clinical impact of valine supplementation on HCV viral load has never been investigated.

Here, we first report a case of HCV-related advanced liver cirrhosis who was treated by valine. The oral administration of valine was associated not only with an improvement of fatigue, but also with a decrease in hepatic fibrosis indexes and serum $\alpha$-fetoprotein (AFP) level. Furthermore, a marked reduction in serum HCV RNA level was seen after treatment with valine. The patient was then treated by interferon therapy, which resulted in the successful eradication of HCV infection. Thus BCAA, particularly valine, may be involved in the reduction of HCV viral load and could support a sustained virologic response to interferon therapy.

\section{Case Report}

A 65-year-old Japanese woman was being treated for HCV genotype 2a-related liver cirrhosis at Kurume University Hospital. Although she had been receiving treatment with ursodeoxycholic acid and a glycyrrhizin preparation for 6 years, the disease was progressive and aggravated to decompensated liver cirrhosis with ascites (Child-Pugh score 10). Since the patient refused liver transplantation, we offered her the option of participating in a phase II clinical trial of oral valine agent (VAL). The study protocol was approved by the Ethical Committee of Kurume University. After obtaining written informed consent, VAL was administered to the patient.

The initial dose of VAL was $3 \mathrm{~g} /$ day. After 4 weeks of administration with the initial dose of VAL, $3 \mathrm{~g} /$ day VAL was added every 4 weeks and the total dose was increased up to $12 \mathrm{~g} /$ day (table 1 , fig. 1). The total VAL administration term was 16 weeks, and the patient completed the clinical trial with $100 \%$ drug compliance. With VAL treatment, general fatigue improved and no drug-related adverse events were seen during the clinical trial. The VAL treatment resulted in the gradual increase in serum valine levels. On the other hand, the serum levels of leucine, isoleucine, tyrosine and phenylalanine were not significantly changed, resulting in an increase in Fischer ratio. No marked changes were observed in the other serum amino acid levels (table 1). 


\begin{abstract}
Although no significant changes were seen in the liver and renal function tests and homeostasis model assessment for insulin resistance, slight increases were seen in the hemoglobin level, white blood cell count and platelet count. The serum aspartate aminotransferase and alanine aminotransferase levels were slightly decreased, and the aspartate aminotransferase to platelet ratio (APRI) and Fib-4 indexes, which are noninvasive indexes of hepatic fibrosis, were also slightly decreased. In addition, the administration of VAL resulted in a marked decrease in serum AFP levels that fell within the reference values by the end of the treatment (table 2). Moreover, the serum HCV RNA levels were significantly decreased from 5.0 to $<1.2 \log$ copy $/ \mathrm{ml}$, in which the qualitative test was positive for HCV RNA. These changes in serum AFP and HCV RNA levels were opposed to the changes in serum valine levels (fig. 1). After the end of the clinical trial, the patient took a commercial BCAA-enriched supplement, and serum HCV RNA levels persistently showed a low titer $(<1.2$ to $3.6 \log$ copy $/ \mathrm{ml}$ ).
\end{abstract}

Two years after the end of the clinical trial, hepatocellular carcinoma (HCC) had developed, which was successfully treated by radiofrequency ablation. Although advanced liver cirrhosis with pancytopenia was present, serum HCV RNA levels persistently showed a low titer. The patient was treated with a total of 300 million units of interferon $\beta 3$ times per week after receiving a detailed explanation of the benefits and risks associated with interferon treatment and giving written informed consent. The serum of HCV RNA then decreased rapidly, and it was no longer detected in the qualitative test 3 weeks after the initiation of interferon therapy. The 36-week interferon treatment resulted in successful eradication of HCV. The patient's Child-Pugh score gradually decreased from 10 to 5 , and no recurrence of HCC has been seen for 5 years.

\title{
Discussion
}

Here, we report a case of HCV-related advanced liver cirrhosis that was treated with VAL. VAL treatment resulted in improvement of fatigue, noninvasive indexes of hepatic fibrosis and serum AFP levels. Concomitantly, HCV viral load was significantly reduced and persistently showed low titer with the subsequent BCAA-enriched supplement. Although advanced liver cirrhosis was seen, the patient was treated with interferon $\beta$, resulting in successful eradication of HCV infection. Thus BCAA, particularly valine, may support a sustained virologic response to interferon therapy through the reduction of HCV viral load.

Patients with liver cirrhosis frequently complain of various symptoms. In our case, the patient experienced fatigue, and this clinical symptom was improved by the VAL treatment. Fatigue is associated with brain levels of 5-hydroxytryptamine, which is a neurotransmitter synthesized from tryptophan [13]. The transport of tryptophan across the blood-brain barrier is the rate-limiting step in the synthesis of 5-hydroxytryptamine, and BCAA is known to compete with tryptophan for transport into the brain [5]. Since serum valine level was markedly increased by VAL treatment in our case, valine may have inhibited the transport of tryptophan into the brain and subsequently improved fatigue through suppression of 5-hydroxytryptamine synthesis in our case.

The APRI and Fib-4 indexes are noninvasive markers for hepatic fibrosis, and the usefulness of these markers has been reported in patients with HCV-related chronic liver disease [14]. In our patient, both APRI and Fib-4 indexes were slightly decreased after VAL treatment. Serum BCAA levels are known to be significantly associated with $\mathrm{HCV}$-related hepatic fibrosis, and BCAA treatment with angiotensin-converting enzyme inhibitor was reported to improve liver fibrosis progression in cirrhotic patients [9]. In addition, Nakanishi et al. [15] investigated the effect of valine on hepatic fibrosis in a carbon tetrachloride-treated rat model of liver cirrhosis and revealed that valine 
treatment results in a significant downregulation of procollagen $\alpha 1$, transforming growth factor- $\beta$ and connective tissue growth factor. Taken together, these findings suggested that VAL treatment may lead to the downregulation of promoting factors for collagen production, resulting in a decrease in hepatic fibrosis indexes in our case.

The serum AFP level was markedly reduced in a dose-dependent manner after VAL treatment in our patient. Previous in vitro experiments have shown that BCAA directly inhibits the proliferation of hepatoma cell lines [16]. Furthermore, valine is known to improve DC function $[9,17]$, which is associated with the progression of human HCC [5]. Moreover, a large-scale randomized controlled trial demonstrated that BCAA suppresses the development of HCC in cirrhotic patients with elevated serum AFP levels [18]. Since AFP level is a predictive marker for hepatocarcinogenesis, VAL treatment may suppress hepatocarcinogenesis, resulting in the reduction of the serum AFP levels in our case.

We first demonstrated that HCV viral load was markedly decreased after VAL treatment in a patient with advanced liver cirrhosis. Although the mechanisms for the VAL-associated reduction in HCV viral load remain unclear, there are three possible explanations. First, DCs are antigen-presenting cells and functional impairment of DCs is associated with poor response to interferon therapy [19]. Valine is known to improve DC function, including interleukin-12 production, in HCV-related cirrhotic patients [9]. Therefore, VAL may contribute to the reduction in HCV viral load through the improvement of immune function. Second, hepatic triglyceride is an important organelle for HCV production and lipid metabolism inhibitors disrupt HCV replication [11]. Since valine depletion causes accumulation of hepatic lipid droplets [10], VAL may modulate hepatic lipid metabolism and subsequently reduce HCV viral load. Third, HCV replication is associated with intracellular interferon signaling, which is partly regulated by mTOR and SOCS3 [20]. Recently, Honda et al. [12] showed that BCAA upregulates intracellular interferon signaling through the activation of mTOR and the suppression of SOCS3 expression, leading to the inhibition of HCV replication in JFH-1-infecting Huh7 cells [12]. Thus, VAL may improve interferon signaling, resulting in a reduction in HCV viral load.

In conclusion, we report a case of HCV-related advanced liver cirrhosis who was treated with VAL. VAL treatment was associated with an improvement of fatigue and a reduction in hepatic fibrosis indexes and serum AFP levels in our patient. Moreover, a significant reduction in serum HCV RNA levels was seen after VAL treatment, and the patient showed a sustained virologic response to the subsequent interferon therapy. Thus BCAA, particularly valine, may be involved in the reduction of HCV viral load and could support a sustained virologic response to interferon therapy.

\section{Acknowledgements}

This study was supported in part by a Grant-in-Aid for Young Scientists (B) (No. 19790643 to T.K.) from the Ministry of Education, Culture, Sports, Science and Technology of Japan, and by Health and Labor Sciences Research Grants for Research on Hepatitis from the Ministry of Health, Labor and Welfare of Japan. 
Table 1. Changes in amino acid profile by VAL treatment

\begin{tabular}{|c|c|c|c|c|c|c|}
\hline \multirow{2}{*}{$\begin{array}{l}\text { Examination } \\
(\mathrm{nmol} / \mathrm{ml})\end{array}$} & \multirow{2}{*}{$\begin{array}{l}\text { Reference } \\
\text { value }\end{array}$} & \multirow[t]{2}{*}{ Before } & \multicolumn{4}{|c|}{ Dose and administration term of VAL } \\
\hline & & & $\begin{array}{l}3 \mathrm{~g} / \text { day } \\
0-4 \mathrm{wk}\end{array}$ & $\begin{array}{l}6 \mathrm{~g} / \text { day } \\
5-8 \mathrm{wk}\end{array}$ & $\begin{array}{l}9 \mathrm{~g} / \text { day } \\
9-12 \mathrm{wk}\end{array}$ & $\begin{array}{l}12 \mathrm{~g} / \mathrm{day} \\
13-16 \mathrm{wk}\end{array}$ \\
\hline Valine & $147.8-307.0$ & 162.1 & 181.9 & 242.3 & 263.1 & 312.4 \\
\hline Fischer ratio & $2.43-4.40$ & 0.95 & 1.02 & 1.32 & 1.38 & 1.51 \\
\hline Leucine & $78-180$ & 85.4 & 76.5 & 71.7 & 52.4 & 78.9 \\
\hline Isoleucine & $40-110$ & 55.0 & 43.0 & 45.0 & 30.5 & 42.2 \\
\hline Tyrosine & $40-90$ & 202.4 & 193.0 & 186.3 & 166.1 & 193.7 \\
\hline Phenylalanine & $43-76$ & 115.3 & 102.3 & 86.1 & 85.4 & 94.1 \\
\hline Taurine & $40-93$ & 61.3 & 56.8 & 64.4 & 54.8 & 63.3 \\
\hline Urea & $2,600-6,600$ & $6,006.0$ & $5,463.0$ & $7,630.2$ & $5,821.3$ & $5,045.6$ \\
\hline Aspartic acid & $<3.0$ & 4.2 & 3.1 & 3.1 & 2.1 & 3.2 \\
\hline Threonine & $67-190$ & 227.5 & 204.0 & 206.5 & 166.8 & 157.2 \\
\hline Serine & $72-160$ & 197.7 & 184.3 & 185.7 & 168.7 & 174.8 \\
\hline Asparagine & $45-97$ & 110.6 & 79.8 & 78.8 & 65.6 & 79.6 \\
\hline Glutamic acid & $12-63$ & 52.9 & 55.3 & 47.5 & 46.4 & 46.7 \\
\hline Glutamine & $420-700$ & 675.7 & 696.0 & 775.3 & 789.5 & 830.2 \\
\hline Proline & $78-270$ & 192.9 & 192.9 & 169.0 & 159.2 & 158.1 \\
\hline Glycine & $150-350$ & 271.2 & 286.5 & 251.8 & 279.5 & 274.8 \\
\hline Alanine & $210-520$ & 412.5 & 355.5 & 349.8 & 447.0 & 465.6 \\
\hline Citrulline & $17-43$ & 52.6 & 56.4 & 54.6 & 56.4 & 68.0 \\
\hline Cystine & $29-49$ & 61.9 & 54.7 & 66.9 & 65.3 & 55.2 \\
\hline Methionine & $19-40$ & 96.3 & 107.4 & 103.8 & 67.9 & 66.7 \\
\hline Monoethanolamine & $<11$ & 12.4 & 18.2 & 20.4 & 19.6 & 20.9 \\
\hline Histidine & $59-92$ & 90.2 & 91.0 & 84.7 & 100.1 & 96.0 \\
\hline$\alpha$-Aminobutyric acid & $7.9-27.0$ & 21.2 & 18.4 & 15.7 & 11.9 & 8.4 \\
\hline Lysine & $110-240$ & 212.5 & 194.4 & 194.6 & 188.6 & 172.5 \\
\hline Tryptophan & $37-75$ & 44.6 & 40.3 & 26.3 & 57.3 & 44.3 \\
\hline Ornithine & $30-100$ & 143.3 & 132.1 & 132.3 & 142.1 & 160.9 \\
\hline Arginine & $54-130$ & 119.8 & 116.5 & 107.6 & 129.4 & 151.8 \\
\hline
\end{tabular}

The following serum amino acid levels were not detected: phosphoethanolamine, hydroxyproline, sarcosine, $\alpha$-aminoadipic acid, cystathionine, $\gamma$-amino- $\beta$-hydroxybutyric acid, $\beta$-alanine, $\beta$-amino-iso-butyric acid, $\gamma$-aminobutyric acid, homocystine, 3-methylhistidine, 1 -methylhistidine, carnosine, anserine, hydroxylysine. 
Table 2. Changes in biochemical parameters by VAL treatment for 16 weeks

\begin{tabular}{|c|c|c|c|}
\hline \multirow[t]{2}{*}{ Examination } & \multirow[t]{2}{*}{ Reference value } & \multicolumn{2}{|c|}{ VAL treatment } \\
\hline & & before & after \\
\hline Red blood cells, $\times 10^{4} / \mathrm{mm}^{3}$ & $430-570$ & 312 & 321 \\
\hline Hemoglobin, g/dl & $14.0-18.0$ & 11.4 & 12.1 \\
\hline White blood cell, $/ \mathrm{mm}^{3}$ & $4,000-9,000$ & 3,000 & 3,400 \\
\hline Platelet, $\times 10^{4} / \mathrm{mm}^{3}$ & $13-36$ & 5.1 & 5.6 \\
\hline Aspartate transaminase, $\mathrm{U} / \mathrm{l}$ & $13-33$ & 53 & 39 \\
\hline Alanine aminotransferase, $U / l$ & $8-42$ & 29 & 20 \\
\hline Lactate dehydrogenase, $\mathrm{U} / \mathrm{l}$ & $119-229$ & 240 & 281 \\
\hline Alkaline phosphatase, $\mathrm{U} / \mathrm{l}$ & $115-359$ & 696 & 699 \\
\hline$\gamma$-Glutamyl transpeptidase, $\mathrm{U} / \mathrm{l}$ & $10-47$ & 31 & 24 \\
\hline Total protein, g/dl & $6.70-8.30$ & 6.40 & 6.86 \\
\hline Albumin, g/dl & $4.00-5.00$ & 2.78 & 2.87 \\
\hline Prothrombin activity, \% & $60-130$ & 46 & 62 \\
\hline Total bilirubin, $\mathrm{mg} / \mathrm{dl}$ & $0.30-1.50$ & 1.93 & 2.52 \\
\hline Blood urea nitrogen, $\mathrm{mg} / \mathrm{dl}$ & $8.0-22.0$ & 17.9 & 14.6 \\
\hline Creatinine, mg/dl & $0.40-0.70$ & 0.70 & 0.71 \\
\hline $\mathrm{Na}, \mathrm{mmol} / \mathrm{l}$ & $138-146$ & 134 & 136 \\
\hline $\mathrm{K}, \mathrm{mmol} / \mathrm{l}$ & $3.6-4.9$ & 4.6 & 4.6 \\
\hline $\mathrm{Cl}, \mathrm{mmol} / \mathrm{l}$ & 99-109 & 103 & 102 \\
\hline Total cholesterol, mg/dl & $128-220$ & 115 & 106 \\
\hline Triglyceride, mg/dl & $38-207$ & 70 & 49 \\
\hline Fasting blood glucose, $\mathrm{mg} / \mathrm{dl}$ & 80-109 & 114 & 115 \\
\hline Immune reactive insulin, $\mu \mathrm{U} / \mathrm{ml}$ & $5-20$ & 19.9 & 20.8 \\
\hline HOMA-IR & $<2.5$ & 5.60 & 5.90 \\
\hline Free fatty acids, $\mu \mathrm{Eq} / \mathrm{l}$ & $100-540$ & 981 & 703 \\
\hline Ammonia, $\mu \mathrm{g} / \mathrm{dl}$ & $12-66$ & 46 & 41 \\
\hline APRI & $\mathrm{N} / \mathrm{A}$ & 3.15 & 2.11 \\
\hline Fib-4 index & $\mathrm{N} / \mathrm{A}$ & 12.5 & 10.1 \\
\hline $\mathrm{AFP}, \mathrm{ng} / \mathrm{ml}$ & $<8.7$ & 69.8 & 5.1 \\
\hline Lectin-reactive AFP, \% & $<10.0$ & 1.1 & ND \\
\hline
\end{tabular}

HOMA-IR = Homeostasis model assessment for insulin resistance; N/A = not applicable; ND = not detected. 

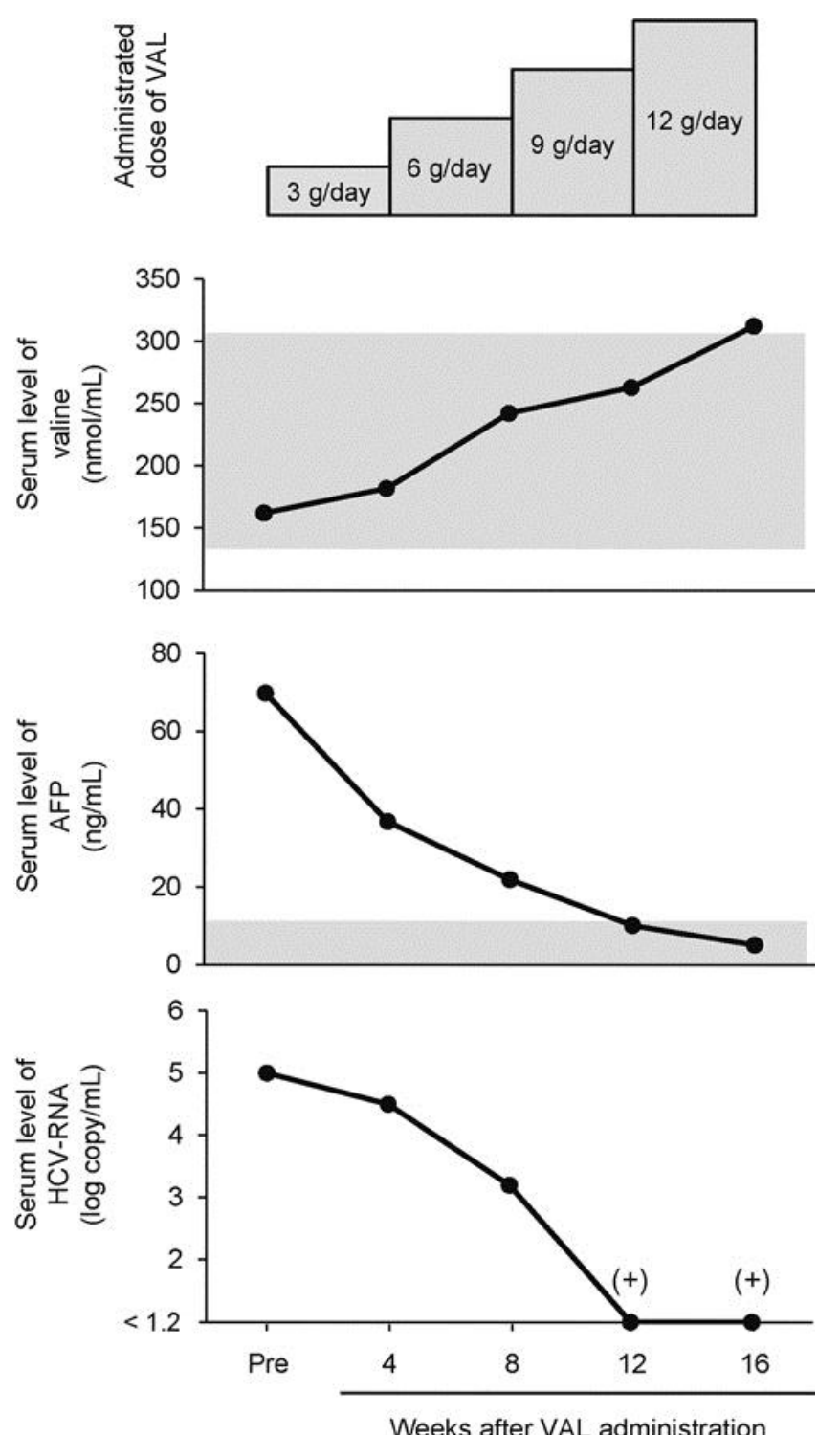

Fig. 1. Time course changes in serum valine, AFP, and HCV RNA levels during VAL treatment. The grey area indicates the reference value of each parameter, and (+) indicates a positive result of qualitative test for serum HCV RNA.

\section{References}

1 Afdhal NH, McHutchison JG, Zeuzem S, et al: Hepatitis C pharmacogenetics: state of the art in 2010. Hepatology 2011;53:336-345.

2 Akuta N, Suzuki F, Hirakawa M, et al: Association of amino acid substitution pattern in core protein of hepatitis $C$ virus genotype 2 a high viral load and virological response to interferon-ribavirin combination therapy. Intervirology 2009;52:301-309.

-3 Cross TJ, Rashid MM, Berry PA, Harrison PM: The importance of steatosis in chronic hepatitis C infection and its management: a review. Hepatol Res 2010;40:237-247.

4 Fattovich G, Covolo L, Bibert S, et al: IL28B polymorphisms, IP-10 and viral load predict virological response to therapy in chronic hepatitis C. Aliment Pharmacol Ther 2011;33:1162-1172. 
5 Kawaguchi T, Izumi N, Charlton MR, Sata M: Branched-chain amino acids as pharmacological nutrients in chronic liver disease. Hepatology 2011;54:1063-1070.

6 Kato A, Suzuki K: How to select BCAA preparations. Hepatol Res 2004;30S:30-35.

7 Moriwaki H, Shiraki M, Fukushima H, et al: Long-term outcome of branched-chain amino acid treatment in patients with liver cirrhosis. Hepatol Res 2008;38:S102-S106.

-8 Kumada $\mathrm{H}$, Okanoue T, Onji M, et al: Guidelines for the treatment of chronic hepatitis and cirrhosis due to hepatitis C virus infection for the fiscal year 2008 in Japan. Hepatol Res 2010;40:8-13.

9 Kakazu E, Kanno N, Ueno Y, Shimosegawa T: Extracellular branched-chain amino acids, especially valine, regulate maturation and function of monocyte-derived dendritic cells. J Immunol 2007;179:7137-7146.

$\checkmark 10$ Komatsu H, Nishihira T, Chin M, et al: Effect of valine-depleted total parenteral nutrition on fatty liver development in tumor-bearing rats. Nutrition 1998;14:276-281.

11 Miyanari Y, Atsuzawa K, Usuda N, et al: The lipid droplet is an important organelle for hepatitis C virus production. Nat Cell Biol 2007;9:1089-1097.

12 Honda M, Takehana K, Sakai A, et al: Malnutrition impairs interferon signaling through mTOR and FoxO pathways in patients with chronic hepatitis C. Gastroenterology 2011;141:128-140, 140.e1-2.

13 Yamamoto T, Azechi H, Board M: Essential role of excessive tryptophan and its neurometabolites in fatigue. Can J Neurol Sci 2012;39:40-47.

14 Vallet-Pichard A, Mallet V, Nalpas B, et al: FIB-4: an inexpensive and accurate marker of fibrosis in HCV infection. Comparison with liver biopsy and fibrotest. Hepatology 2007;46:32-36.

15 Nakanishi C, Doi H, Katsura K, Satomi S: Treatment with L-valine ameliorates liver fibrosis and restores thrombopoiesis in rats exposed to carbon tetrachloride. Tohoku J Exp Med 2010;221:151-159.

-16 Hagiwara A, Nishiyama M, Ishizaki S: Branched-chain amino acids prevent insulin-induced hepatic tumor cell proliferation by inducing apoptosis through mTORC1 and mTORC2-dependent mechanisms. J Cell Physiol 2012;227:2097-2105.

17 Kakazu E, Ueno Y, Kondo Y, et al: Branched chain amino acids enhance the maturation and function of myeloid dendritic cells ex vivo in patients with advanced cirrhosis. Hepatology 2009;50:1936-1945.

18 Muto Y, Sato S, Watanabe A, et al: Overweight and obesity increase the risk for liver cancer in patients with liver cirrhosis and long-term oral supplementation with branched-chain amino acid granules inhibits liver carcinogenesis in heavier patients with liver cirrhosis. Hepatol Res 2006;35:204-214.

19 Liang CC, Liu CH, Lin YL, Liu CJ, Chiang BL, Kao JH: Functional impairment of dendritic cells in patients infected with hepatitis $C$ virus genotype 1 who failed peginterferon plus ribavirin therapy. J Med Virol 2011;83:1212-1220.

20 Kawaguchi T, Yoshida T, Harada M, et al: Hepatitis C virus down-regulates insulin receptor substrates 1 and 2 through up-regulation of suppressor of cytokine signaling 3. Am J Pathol 2004;165:1499-1508. 